\title{
Feminism and the Politics of Resilience: Essays on Gender, Media, and the End of Welfare
}

\author{
Angela McRobbie Cambridge, UK: Polity Press, 2020 (ISBN 978-1- \\ 5095-2507-2)
}

\author{
Robin James \\ Department of Philosophy, University of North Carolina, Charlotte, North Carolina, USA \\ Email: Robinmjames7@gmail.com
}

Though she doesn't use exactly these terms, Angela McRobbie's Feminism and the Politics of Resilience: Essays on Gender, Media, and the End of Welfare is about how early twenty-first-century British neoliberalism transforms the classic virgin/whore dichotomy into one between so-called "mom bosses" and "welfare queens." A focused complement to Melinda Cooper's Family Values: Between Neoliberalism and the New Social Conservatism and Laura Briggs's How All Politics Became Reproductive Politics (which both focus on the US), McRobbie's book shows how the reframing of (white, cis) normative femininity around neoliberal logics of private responsibility is one of neoliberalism's central projects. Methodologically, the book is informed primarily by Stuart Hall and to a somewhat lesser extent by Michel Foucault and Wendy Brown. As the subtitle suggests, the book is a collection of four fairly self-contained essays on the underlying theme of the popular media's gendering of neoliberal private responsibility.

In chapter 1, "Feminism, the Family and the New Multi-Mediated Maternalism," McRobbie argues that in the new millennium, the figure of the "professionalized" mother has become a key tool for conscripting white (presumably cis) women to their role in racial capitalism. The professionalized mother runs her "corporate family" (31) like a CEO. Focused on "careful financial planning, good self-governance to insure against family breakdown and... non-reliance on the state or on benefits and a female head of household who can 'do it all' even if she cannot quite 'have it all'" (31-32), this new feminine ideal reworks traditional feminine gender norms like chastity into neoliberal notions of private individual responsibility. She writes, "what was in the Victorian era a moral high ground of imperialist maternal citizenship is now recast as a no-less-moralistic playground of lifestyle and consumer culture, predicated on young women making the right choices and adopting, at an early age, the right kind of life-plan" (40). For example, women's domestic work is still oriented to preserving "the "future of the race" (29), but that future is measured less in terms of population hygiene and more in terms of private individual responsibility (or what Cooper calls "legitimacy"). As McRobbie explains, twenty-first-century British media thrives on shaming poor women for their supposedly unkempt appearance, but treats it less as

(c) The Author(s), 2022. Published by Cambridge University Press on behalf of Hypatia, a Nonprofit Corporation 
evidence of poor health and more as evidence of one's inability to exercise the kind of personal responsibility necessary to keep oneself and one's family off public assistance. "The future of the race" depends on (white, cis) women's ability to privatize the costs of their sexual choices (that is, children). At the same time, this feminine ideal puts women who rely on public assistance outside the bounds of full, proper whiteness, much in the same way sexual abnormality did in the Victorian era. So, the "professional mom" is a gender norm that racializes some women as white (or white enough) and others as nonwhite and thus deserving of punishment and criminalization. For McRobbie, this policing or "work of family responsibilization, at least in the UK, is entrusted to the feminine mass media and popular culture" (34), such as newspapers, websites, and social media. McRobbie singles out an epicenter of the contemporary anti-trans movement, mumsnet.com, as the media outlet/platform that "most precisely embodies" (21) the discourse of professionalized motherhood, but unfortunately she doesn't consider the relationship between this discourse and the recent explosion of trans-exclusionary feminism for which mumsnet is significantly responsible. Such an analysis would be especially helpful for feminist philosophers, given the deep ties some academic feminist philosophers in the UK have to anti-trans feminisms because it would clarify yet another way that trans-exclusionary feminism is ultimately a project aimed, like the discourse of professionalized motherhood, at the racist, imperialist project of maintaining the "future" of the white race.

Chapter 2, "Feminism and the Politics of Resilience," focuses on what McRobbie calls the "perfect-imperfect-resilience" ( $\mathrm{p}$-i-r) dispositif (52) in contemporary British pop culture. Studying an array of British women's magazines and pop-psychology literature, McRobbie distinguishes among these three forms of popular feminist practice. "The perfect" is a form of neoliberal feminism that is "predicated on intense competition" (45) and "relies on an inner-directed compulsion to compete with herself, in order to exude an exemplary mode of feminist leadership" (48). The "imperfect" and "resilience" are counterparts to the perfect that "help women to step back from hard-edged leadership-feminism" (56) by rendering imperfect femininity legible and acceptable. Together, these three forms of feminist practice have three main functions. First, they domesticate recently resurgent feminist activism without letting on that's what they're doing: everybody gets to have a little feminism, as a treat, but that feminism doesn't disrupt underlying gender, race, and sexual relations. Second, these forms of feminist practices do "disrupt" in the Silicon Valley sense of the term: "The p-i-r. . . inject[s] into feminine consumer culture an element of innovation that derives from a new wave of feminist activism" (63). And finally, the p-i-r subjectivizes individual women into neoliberal self-responsibility and uses "feminist" resilience as a way to sell individual and family responsibility as feminist and therefore good. At the end of the chapter, McRobbie argues that the way to fight back against and resist the p-i-r is by using psychoanalysis and/or "great literature" to "contes[t] the idea of a unified, autonomous and transparent self" by seeing the self as "relational" (70). Focused on the individual self and individuals' concept of their selves, this proposed fix, like the p-i-r itself, mistakenly frames political problems of white-supremacist capitalist patriarchy as problems inside the minds and psyches of women. I was disappointed that an otherwise solid analysis of feminism and resilience discourse didn't stick its landing.

Chapter 3 is titled "Out of Welfare: Women and 'Contraceptive Employment." This chapter argues that in the UK, various government policies and media strategies have used a nominally "feminist" championing of women's paid work to both shrink the welfare state and shape public opinion in favor of such shrinking. As McRobbie 
puts it, "in the UK work is foregrounded as the means by which the family is enabled to shoulder the burden of the social goods once provided by the state" (75). Shrinking the welfare state and demonizing those who can't bootstrap themselves into private individual responsibility is one of neoliberalism's overarching goals. One of the key contributions of McRobbie's analysis in this chapter is its focus specifically on the UK: unlike the more thoroughly studied US context, the UK foregrounds work rather than family responsibility as the thing individuals should turn to in place of the state (87-91). The chapter's other key contribution is McRobbie's analysis of how work gets mobilized in this way. According to McRobbie, a combination of government policy and visual media culture work together to reinforce the perception that good women subordinate family care obligations to their obligation to work. She explains

This is a complex terrain where social policy and public health both work seemingly by stealth or behind the scenes to reshape family life so it accords with the requirements of the new economy.... It is within the media and celebrity driven popular culture that these encouragements take place, where specifically middle-class and white norms of successful femininity require the putting off of having children until "the time is right." (78)

While policy quietly compels women toward work, workfare, and the reproductive choices that best support those, the popular media promulgates what McRobbie calls an "imaginary of anti-welfarism" (81) that shames women for the appearance of poor personal responsibility (for example, unfashionable clothes, body size and shape, and so on). This idea of an "imaginary of anti-welfarism" will be useful for scholars of culture and media in thinking about how neoliberalism continues to (re)shape the elements and discourses of various media and vernaculars.

When I finished chapter 3, I felt that McRobbie's point would be clearer and better grounded with some close analysis of concrete examples, and the next chapter delivers some of that. Chapter 4, "Breaking the Spell of the Welfare State: Gender, Media and Poverty-Shaming," argues that postmillennial TV shows such as Little Britain and Benefits Street "have consistently portrayed poor people, and especially women, in derogatory ways, as a drain on the nation's resources and as undeserving of compassion and as unworthy of protection" (99). According to McRobbie, this televisual convention has become a "structure of feeling" (105) that legitimates antiwelfare reforms to social policy by framing poor people as undeserving and as insufficiently self-responsible. The chapter focuses largely on representations of poor white women as welfare cheats, both because such stereotypes have a long history of being applied to women of color (especially Black women) and because their focus on white women is strategic. As McRobbie explains, "the white poverty-shamed woman expedites the cuts in welfare that impact disproportionately on black and other ethnic minority populations" (120). The poverty-shaming spectacle focuses on white women to disguise its ultimately racist motivations and effects. This chapter shows how the media is a crucial element of the politics of austerity and private responsibility.

Throughout the book, McRobbie argues that this gendered poverty-shaming produces "a female incarceration effect" whereby "the most vulnerable sectors of the population are not just made to suffer, but are increasingly and incrementally deprived of resources which would permit any improvement to their dire circumstances" (121). In the book, "incarceration" means "confined from." However, because of both the technical use of the term in the academic subfield of carceral studies and the fact 
that even in a nontechnical sense the term connotes injustice disproportionately experienced by nonwhite people, McRobbie's analysis would be stronger if she pushed both of these senses of the term more fully. Doing so would further clarify how the gender stereotypes and gendered logics she analyzes are also racial and racializing ones. Also, especially given the concentration of trans-exclusionary feminism in the UK, McRobbie's analysis would have been stronger and more useful if it had considered how the neoliberal feminisms she studies in the book take cis women as their ideal subject.

Though it is short and essay-focused, this is not a book for introductory or lower-level classes, or for any context where readers don't already know what technical academic terms like dispositif mean. McRobbie's book is a valuable contribution to the growing scholarly literature on gender, feminism, and neoliberalism. Because of its narrow focus on the UK, it is especially helpful in tracking how neoliberal popular feminisms and discourses of private responsibility vary across national contexts. It also opens out the question of how media practices, conventions, and aesthetics adapt to embody and enforce the neoliberal imperative to private responsibility, a question I am interested in in my own work and that I look forward to reading more about in future scholarship from others.

Robin James is an Associate Professor of philosophy at the University of North Carolina, Charlotte. She is the author of three books: The Sonic Episteme: Acoustic Resonance, Neoliberalism, and Biopolitics (Duke University Press, 2019), Resilience and Melancholy: Pop Music, Feminism, and Neoliberalism (Zero, 2015), and The Conjectural Body: Gender, Race, and the Philosophy of Music (Lexington Books, 2010). Her work on feminism, race, contemporary continental philosophy, pop music, and sound studies has appeared in venues such as The Guardian, LARB, BELT Magazine, The New Inquiry, SoundingOut!, Hypatia, Differences, and the Journal of Popular Music Studies. 